Sādhanā Vol. 40, Part 4, June 2015, pp. 1283-1299. (C) Indian Academy of Sciences

\title{
Study of a $30 \mathrm{MW}$ bubbling fluidized bed combustor based on co-firing biomass and coal
}

\author{
HEMANT KUMAR $^{1, *}, \mathrm{~S} \mathrm{~K} \mathrm{MOHAPATRA}^{2}$ and \\ RAVI INDER SINGH ${ }^{3}$
}

${ }^{1}$ Department of Mechanical Engineering, Punjabi University, Patiala 147 002, India

${ }^{2}$ Department of Mechanical Engineering, Thapar University, Patiala 147 004, India

${ }^{3}$ Department of Mechanical Engineering, Birla Institute of Technology and Science, Pilani 333 031, India

e-mail: htdhiman@gmail.com

MS received 23 October 2012; revised 16 May 2014; accepted 06 February 2015

\begin{abstract}
Today's power generation sources are largely dependent on fossil fuels due to which the future sustainable development has become a challenge. A significant amount of the pollutant emissions such as carbon dioxide, carbon monoxide and nitrogen oxide from the power sector is related to the use of fossil fuels for power generation. As the demand for electricity is growing rapidly, emissions of carbon dioxide and other pollutants from this sector can be expected to increase unless other alternatives are made available. Among the energy sources that can substitute fossil fuels, biomass fuels appear as one of the options with a high worldwide potential. In the Punjab region of India, Fluidized-bed combustion technology is being used for converting biomass into thermal energy and power generation in various small scale units. The investigation of biomass-based plant through experimental activities and numerical simulation is the scope of this study. The investigations were done at Captive Power Plant (CPP), Ambuja Cement Limited, a project of Holcim, District Ropar, India. During experimental investigations, the study of bed temperatures and steam temperatures at different zones has been done for coal fired and biomass fired combustors with $30 \%$ share. No clear effects of co-firing on boiler performance are observed. However, the operational behavior of the boiler in terms of bed temperature and stack emissions shows a different trend. During simulation, the contours of temperature have been obtained for both the boilers and the trends are found in agreement with real process.
\end{abstract}

Keywords. CFD; biomass; fluidized bed; combustion.

*For correspondence 


\section{Introduction}

There are drastic changes in the composition and behavior of our atmosphere due to the rapid release of polluting combustion products from fossil fuels. A significant amount of the carbon dioxide emissions from the energy sector is related to the use of fossil fuels for electricity generation. The increasing and drastically growing demand of electricity has also increased the possibility of rapid emissions of carbon dioxide and other pollutants from this sector and can be expected to continuously increase unless other alternatives are made available. Also, the declining energy supplies and severely affected environmental conditions due to the emission of these pollutants force us to sharply focus our attention on the need for additional amounts of clean energy sources. Among the energy sources that can substitute fossil fuels, biomass fuels appear as the option with the highest general worldwide potential. In both the developed and the developing countries, the interest and activity for obtaining energy from biomass has expanded tremendously and dramatically in the last few years.

There are large quantities of residues, associated with agricultural production and processing industries and they can be used for energy production, provided that they satisfy the criteria of plentiful supply and local availability on a renewable and perpetual basis. In the Asia-Pacific region, these residues are in plenty since a wide range of crops are grown to produce food for $56 \%$ of the world's population living in this part of the world (Natrajan et al 1998). Power generation based on biomass holds a considerable promise in Punjab, which has huge biomass resources from crop production system and agro industries. The total biomass production in Punjab was estimated at about 54.54 million tonnes (Kaur et al 2006). Out of the total 54.54 million tonnes, 30.26 million tonnes of biomass remains available for power generation. In Punjab, there is a total potential of $2000 \mathrm{MW}$ of power that can be generated from the surplus biomass.

Unlike fossil fuels, which are limited in availability, these residues are not only abundantly available, but also renewable. The utilization of many agricultural residues is not economically viable because of the huge investments required for collection, transportation and storage. However, there are some biomass residues concentrated at specific locations, where demand for energy also exists.

Fluidized-bed combustion process seems to be suitable technology for converting it into thermal energy and power generation. Gas fluidized beds are widely used in industry to achieve either physical processing or chemical reactions that require interfacial contact between gas and solid particles. The most prevalent type of fluidized bed is the bubbling bed wherein particles are retained in the bed while the gas passes upward through the interfacial spaces and as rising bubbles. Many of the applications require heat transfer between the fluidized bed material and immersed surfaces in order to achieve energy balance.

Due to high cost and more time consuming experimentation on fluidization, more researchers are extending their efforts towards developing the mathematical model and numerical simulation with the help of Computational Fluid Dynamics (CFD) and validating the results either with experimental results or real process. In this way, they are able to study large number of parameters in stipulated time and develop the optimized solution to work. These models serve as tools when characterizing reactive flow processes that complement and in, some cases, replace physical experiments with equivalent numerical experiments. Information available from model predictions can include the temperature distributions, gas composition, velocity profiles and more. 


\subsection{Literature review (Combustion of biomass and coal)}

Theinvestigations and studies of various researchers in the field of co-combustion of biomass and coal have been studied and presented in this paper. Demires (2005) described the environmental impact of cofiring of biomass with coal. The cofiring of biomass with coal has a capability to reduce the cost of fuel and emission of $\mathrm{NO}_{\mathrm{x}}$ and $\mathrm{SO}_{\mathrm{x}}$. A bench scale bubbling fluidized bed combustor consisting of a quartz glass tube of diameter $25 \mathrm{~mm}$ and height $650 \mathrm{~mm}$ has been used. The proportion of biomass with coal vary from $5 \%$ to $25 \%$. It describes five major issues associated with cofiring: ash deposition, $\mathrm{SO}_{2}$ emission, $\mathrm{NO}_{\mathrm{x}}$ formation, corrosion and carbon burnout. Average ash, fixed carbon and volatile material contents of fuel species were determined in the study. Madhiyanon et al (2009) investigated the performance of co-combustion of rice husk with coal in a cyclonic fluidized bed combustor. An experimental setup having capacity of $120 \mathrm{~kW}$ has been used for study. The combustion characteristics of rice husk and coal at different proportions were evaluated. The emission and combustion efficiency were also correlated with various ratios of excess air and fuel blends. Sathitruangsak et al (2009) studied the performance of rice husk cofiring in a short combustion chamber fluidized bed combustor. An experimental setup of $250 \mathrm{~kW}$ capacity was designed. Rice husk and coal are fed separately in combustor. Rice husk and coal were cofired at different fluidization velocities. Fluidization velocity affects the gas emissions other than $\mathrm{NO}_{\mathrm{x}}$ which increases with a content of fuel mix. Due to increase in fluidization velocity, the occurrence of insufficient burning time and drop in bed temperature were observed. Sun et al (2013) studied the effect of wide size crushed biomass pellets used in cofiring on emissions, combustion efficiency and bed-to-wall heat transfer in circulating fluidized bed (CFB). The influences of biomass share on bed pressure, temperature profiles, fly ash loss, heat transfer, and gaseous pollutant emissions were studied by experiments performed in a $0.2 \mathrm{MW}$ pilot scale CFB. Results show that with higher biomass share, more uniform axis temperature profiles, lower fly ash loss, less gaseous emission and higher bed-towall heat transfer can be achieved, but the effect of biomass share on bed pressure and porosity is minor. As biomass share increases, a reducing atmosphere is formed at the upper part of the dense zone and the temperature at the lower part is decreased. This inhibits the formation of $\mathrm{NO}_{\mathrm{x}}$ and $\mathrm{SO}_{2}$ in the dense zone and promotes their reduction, so lower gaseous emissions are obtained. Werther et al (2000) explained that cofiring can be carried out in any furnace system, although some modifications may be necessary in order to accommodate the nature of combustion of the agricultural residues. An important factor of consideration is the residue feeding system. Due to low bulk densities, biomass fuels are generally difficult to feed. This is particularly valid in small-scale combustion units. There are problems of blockage and discontinuous feeding if screw feeders are used. In such cases, pneumatic feeding systems may be considered. For all types of fluidized beds the modifications which may be required include, choosing a distributor plate which leads to better solids mixing, injection of combustion air in several stages (e.g. in the bed and in the freeboard), using swirl techniques for the injection of secondary air into the freeboard and using inclined walls in the freeboard to encourage gas recirculation and turbulence.

\section{Experience at CPP}

Captive Power Plant, Ambuja Cement limited, Punjab has the distinction of being the first successful project in HOLCIM group in India. CPP is the internal unit of Ambuja Cement limited, a pioneer cement production company of India. The plant capacity is $30 \mathrm{MW}$. It is necessary to 
Table 1. Plant parameters.

\begin{tabular}{ll}
\hline Capacity & $30 \mathrm{MW}$ \\
Type of bed & AFBC \\
Bed temperature & $750-800^{\circ} \mathrm{C}$ \\
Bed cross-sectional area & $41 \mathrm{~m}^{2}$ \\
Steam temperature & $495^{\circ} \mathrm{C}$ \\
Feed water temperature & $172^{\circ} \mathrm{C}$ \\
Distribution plate & Nozzle type \\
Bed material & Crushed refractory \\
Fuel used & $70 \%$ coal with $30 \%$ Biomass \\
Fly-ash collector & ESP \\
Fuel feed rate & $11 \mathrm{~T} / \mathrm{h}$ \\
Fuel density & $100-105 \mathrm{~kg} / \mathrm{m}^{3}$ \\
\hline
\end{tabular}

mention here that Ambuja not being government organization has taken upon itself the corporate social responsibility to use sustainable fuel for power generation so as to indulge the social benefits of nearby regions in the form of employment of local people or farmers by engaging them in collection and selling of the agro residues to the industry, which otherwise goes waste and produce adverse effects on environment if burnt in open. Different parameters of plant are given in table 1. In 2005, the plant worked on $100 \%$ usage of Rice Husk, for which they received successful CER verification.

Rice husk is a processed fuel from industry and user friendly being clean and available in ready to use size (length $=6 \mathrm{~mm}$ and width $=0.5$ to $1 \mathrm{~mm}$ approximately) whereas other biomass fuels are available in random sizes and require further processing to bring it to required size of $6 \mathrm{~mm}$ (used at CPP). Due to this reason, the number of buyers of rice husk has surpassed the number of suppliers in the region and it became difficult to run the plant on rice husk alone throughout the year due to lesser availability. Initially, when the technological developments were not capable enough to adopt the rice husk as a regular fuel it was treated as a waste by the farmers and rice producing firms and supplied to the newly emerged technology based plants at a very reasonable cost. With the passage of time as the demand for biomass fuel increased, for rice husk in specific, its cost surpassed the cost of conventional fuel as well other biomass fuels. The rice husk costs Rs. 1.30 approximately for 4.2 MJ of energy generation. On the other hand, the cost of other biomass fuels is around 85 paisa for equal amount of energy generation. Hence, they started using different biomass fuels at CPP which are mentioned in table 2. As Ambuja

Table 2. Various biomass fuels used at CPP.

\begin{tabular}{lclc}
\hline Type of fuel & NCV $(\mathrm{Kcal} / \mathrm{kg})$ & Type of fuel & NCV $(\mathrm{Kcal} / \mathrm{kg})$ \\
\hline Rice husk & 3462 & Maize cobs & 2935 \\
Lantena & 3642 & Sunflower husk & 3254 \\
Mustard stalk & 3627 & Mill reject coals & 1626 \\
Wood bark chips & 2000 & Cotton stalk & 3734 \\
Cow dung cake & 2621 & Waste cotton & 3620 \\
Wood chips & 2600 & Waste glucose carbon & 3630 \\
Sunflower stems & 3480 & Sugar mill waste & 2461 \\
Average & 3049 & & \\
Coal & 3500 & & \\
\hline
\end{tabular}




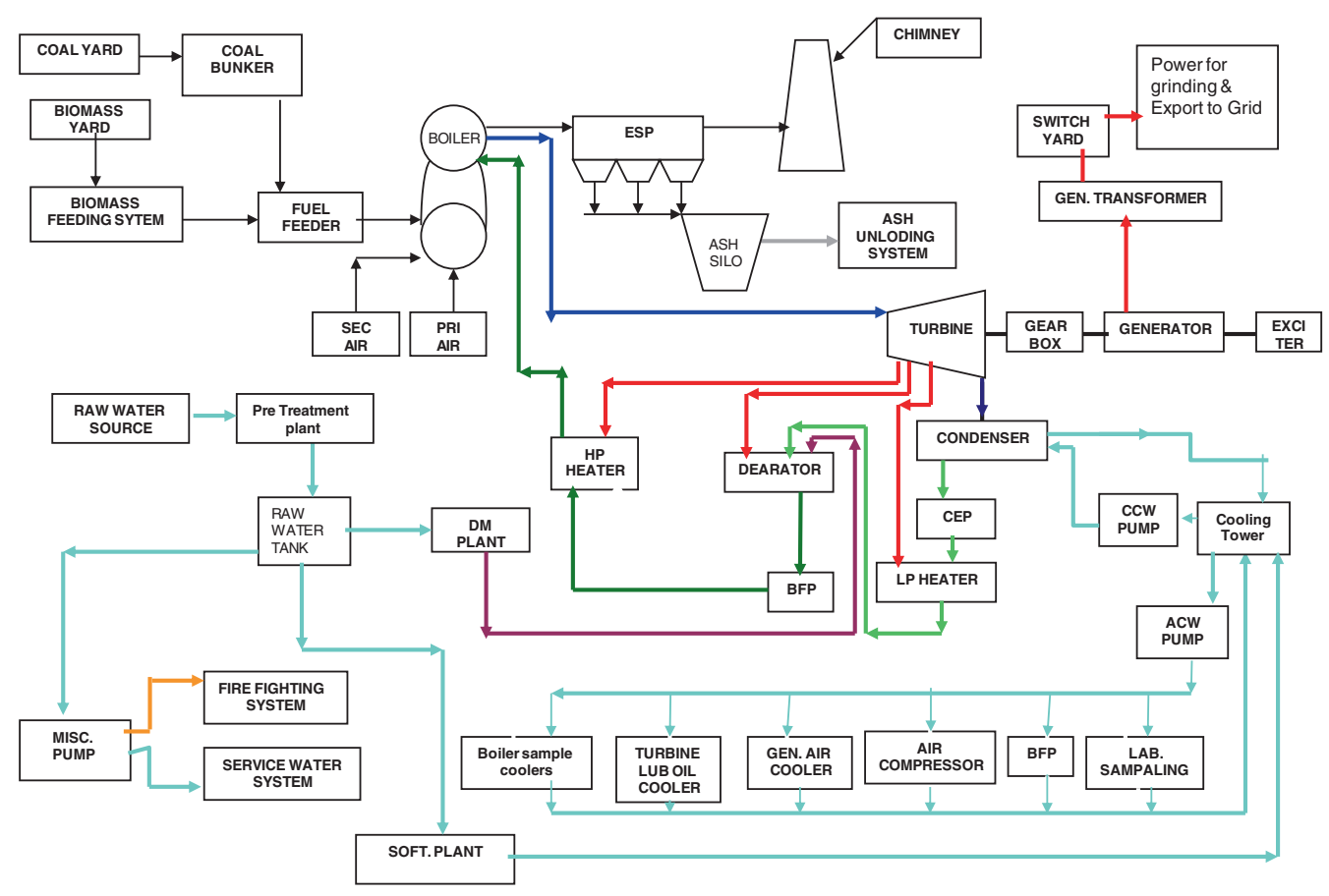

Figure 1. Process layout of CPP.

is primarily a cement producing organization, the bed ash disposal remains no issue for CPP, Ambuja. Bed ash and unburnt obtained from flue gases is collected in the ash silos with the help of pneumatic conveyers from where it is supplied to the clinker silos (in cement production unit) to mix with it which is used in the formation of cement. Biomass handling Plant capacity of the unit is $25 \mathrm{tph}$. They are having UCCI limited ash handling plant, having dense phase conveying system.

CPP is using different fly ash, coarse ash and bed ash silo's modified with MBL dome and blow valves. The plant is using fluidized bed combustor of 45TPH which runs over both biomass and coal. Fuel is fed to the conveyor belt through rollers and from the conveyor belt it is fed to the boiler for incineration. Due to less availability of any particular biomass, they are always used in mixture. The process layout of the plant is shown in figure 1.

\subsection{Different fuel usage at CPP}

Biomass fuels primarily have Woody and Non-Woody forms. Woody biomass includes chips and buckles and Non-Woody forms are divided into two further categories viz. biomass from field agro residues like paddy straw, sugarcane trash and stalks. The other is from industrial agro wastes like rice husk, bagasse and groundnut shell. A few of biomass fuels used at CPP are shown in figure 2. Different biomass fuels are fed to the boiler with fuel feeders.

CPP, Ropar initiated in using different biomass fuels (listed in table 2) to promote preservation of natural recourses and reduction in usage of fossil fuels. The ultimate analysis and proximate analysis of various biomass fuels used has been done and shown in table 3 and table 4 respectively. 


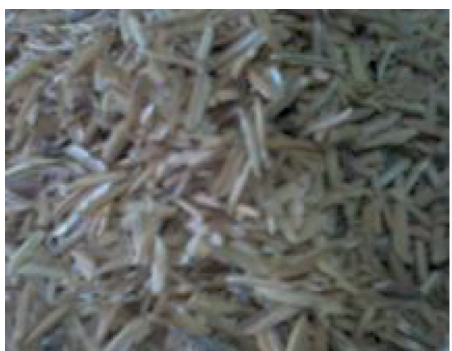

(a)

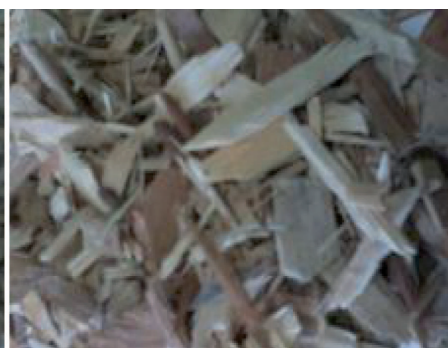

(b)

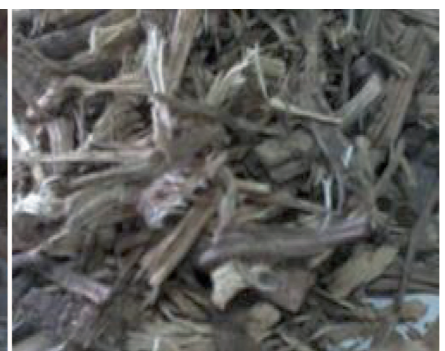

(c)

Figure 2. (a) Rice husk. (b) Wood chips. (c) Lantena.

\subsection{Challenges in usage of biomass fuels}

Although due to the above said benefits of using bio fuels into the field of energy generation, yet few challenges are also found in using biomass fuels which are listed below:

- Ash evacuation problem from ash hoppers of the boiler takes place due to high alkali content and sticky properties of ash.

- It is observed that dome valve seat undergoes frequent damages and cutting due to high silica present in biomass fuels.

- After burning of saw dust, fouling and hard soot deposits in super heater area are found.

- After using dung flakes, fouling effects are found in APH tubes as shown in figure 3.

\subsection{Experimental observations}

CPP, Ambuja generates $30 \mathrm{MW}$ of power running on three units. Two units are having capacity of $45 \mathrm{TPH}$ and one having capacity of $80 \mathrm{TPH}$. The investigations have been done on $45 \mathrm{TPH}$ boilers. All the boilers are designed for biomass combustion. However, in case of less availability of biomass fuel they may run on coal. Here, a comparison of $100 \%$ rice husk usage (using data of 2005) has been done with co-firing and coal usage in terms of power generation and emissions. Test runs are not done for rice husk because it is not presently in use. During study, it was observed that the air consumption in case of biomass combustion was more as compared to conventional fuel, because biomass contains high volatile content up to $75 \%$ and burns in the gas phase in freeboard region, on the other side most of the coal combustion takes place on the bed in the form of char due to less volatile content, up to $25 \%$. Due to this reason, bed temperature in

Table 3. Ultimate analysis of various biomass fuels.

\begin{tabular}{lrccccc}
\hline Fuel & Coal & Rice husk & Saw dust & Wood chips & Cotton stalks & Mustard stalk \\
\hline Carbon & 36.22 & 35 & 31 & 35 & 41 & 43 \\
Hydrogen & 2.64 & 3 & 3.7 & 5 & 4 & 6 \\
Nitrogen & 1.09 & 1.25 & 0.4 & 0.65 & 0.4 & 0.28 \\
Sulphur & 0.55 & 0.18 & 0.17 & 0.05 & 0.1 & 0.07 \\
Moisture & 4.39 & 12 & 25 & 20 & 25 & 5 \\
Ash & 47.86 & 15 & 5 & 5 & 5 & 5.1 \\
Oxygen & 7.25 & 34.45 & 35 & 34 & 25 & 40 \\
GCV(Kcal/kg) & 3500 & 3500 & 3400 & 3600 & 3400 & 3300 \\
\hline
\end{tabular}


Table 4. Proximate analysis of biomass fuels.

\begin{tabular}{lcccc}
\hline Fuel & Coal & Paddy reject & Cow dung cake & Rice husk \\
\hline Moisture & 4.39 & 9.93 & 8.75 & 5.22 \\
Ash & 47.86 & 13.43 & 39.89 & 14.54 \\
Volatile & 17.97 & 65.48 & 41.63 & 66.4 \\
Fixed carbon & 29.78 & 11.16 & 9.73 & 13.84 \\
\hline
\end{tabular}

case of biomass fuel remains less as compared to conventional fuel. Bed temperatures at different eight sections of both the boilers running on coal and biomass in share were obtained and shown in figure 4. A clear increase in the bed temperatures of coal fired boiler is observed as compared to co-firing boilers. Keeping that in mind the bed height in case of biomass fuel is kept less, as if the bed height in case of biomass is kept more the overall temperature of furnace falls down and combustion quality deteriorates in that case.

In case of coal, at least $500^{\circ} \mathrm{C}$ temperature is required to maintain on the bed for initiating the combustion. To maintain a certain high temperature limit in case of coal, the bed height is kept more so that to accommodate more bed material and to control the bed temperature. If the bed height is not increased, then fusion starts at the bed and agglomeration takes place which is not required.

The variation of steam temperatures presented is slightly high in case of coal firing as shown in figure 5. The comparison of monitored data during the testing period and the standard operation in the whole day shows that biomass cofiring does not have any direct impact on plant operation, since the variation of the monitored values stays within the permissible range in the entire day and is not affected by the cofiring tests. As a general result, it is stated that biomass cofiring does not have a significant effect on the operational behavior of the specific boiler. However, a slight variation in the average values of flue gas emissions during the investigation is observed which are given in table 5. The increased percentage of $\mathrm{O}_{2}$ in the flue gas in case of rice husk and cofiring is an indication of the increased amount of secondary air entering into the boiler.

$\mathrm{NO}_{\mathrm{x}}$ values tend to increase in case of coal firing as temperature remains on higher side in case of coal firing. These higher temperatures provide an explanation for increased tendency of $\mathrm{NO}_{\mathrm{x}}$ levels. $\mathrm{CO}$ emissions were found almost the same in both the cases. $\mathrm{CO}_{2}$ emissions are

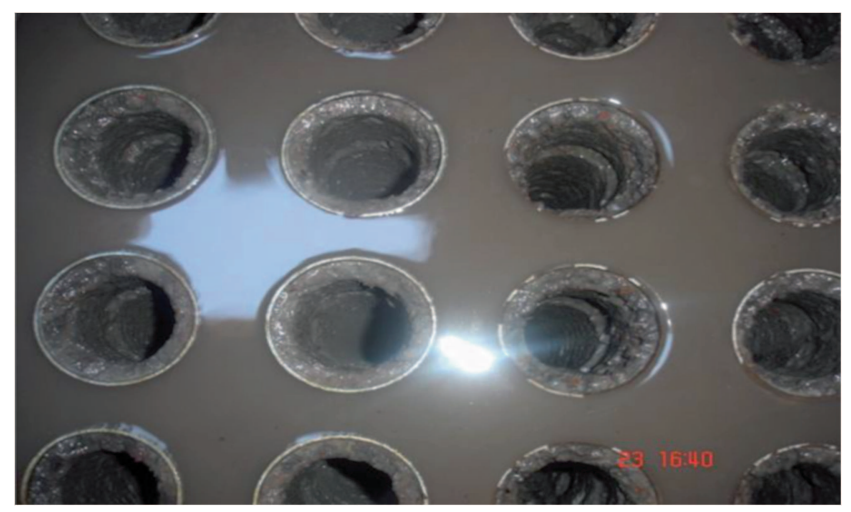

Figure 3. Soot deposits inside APH tubes. 


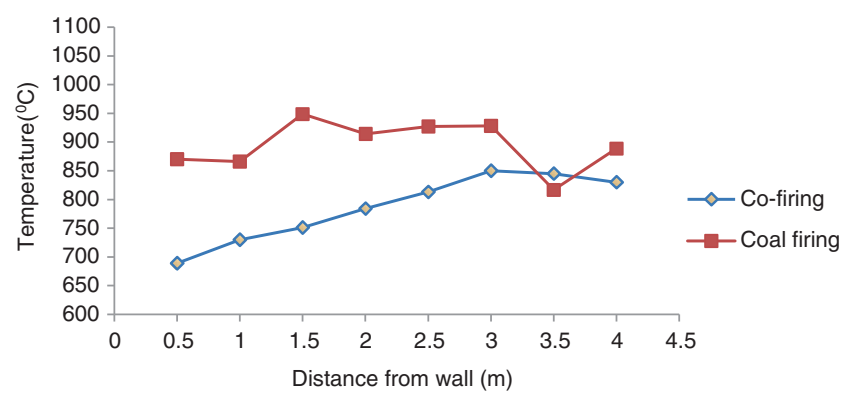

Figure 4. Temperature profiles of the bed.

estimated based on the carbon content as obtained from the elemental analysis of the fuel and the excess air used at the power plants. One tonne of biomass fuel replaces around 0.85 tonnes of coal \& therefore saves equal amount of $\mathrm{CO}_{2}$ emissions (Indian Network for Climate Change Assessment 2010). $\mathrm{SO}_{2}$ formation does not depend upon the combustion conditions inside the furnace but depends upon the sulphur content of the fuel. In case of biomass sulphur content remains negligible around 0.18 (\% by wt.) and f-grade coal is used at CPP which is also having very less sulphur content which is 0.35 (\% by wt.). So the $\mathrm{SO}_{2}$ formation in case of biomass fuel remains within the permissible limits which are about $50 \times 10^{-3} \mathrm{~g} / \mathrm{MJ}$ (Demires 2005).

\subsection{Technology evolved in $C P P$}

Different technological developments are required for successful implementation of biomass fuel at the plant. CPP, Ambuja has implemented a number of these which are summarized as

- Fuel conveying system was modified to cater to the needs of variety of biomass fuels.

- The boilers were modified to over bed fuel feeding mode to make them versatile for burning different types of biomass fuels.

- On line soot blowers were installed to mitigate the fouling effects of ash.

- Locally developed Grabber is fitted on tractor which lifts the lantana bushes and feeds to shredding machine.

- Belt weighers were installed to monitor the flow of biomass fuels.

- Instrumentation control loops were tuned to take care of variations in the fuel feed material.

- Locally developed dung flakes crusher is installed which crushes the flakes and feeds "on line" to the next conveyor.

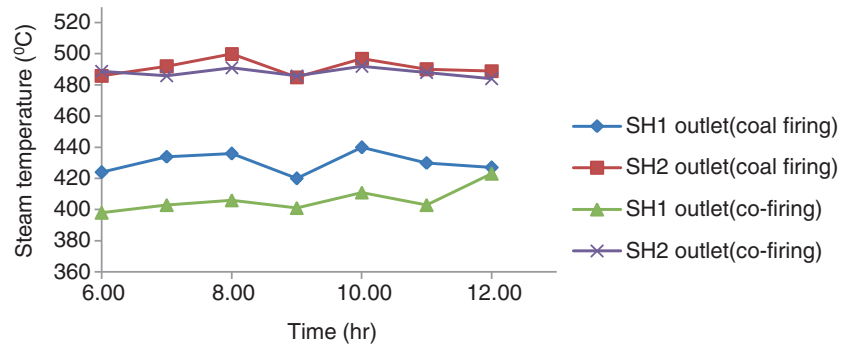

Figure 5. Records of steam temperatures. 
Table 5. Flue gas emissions.

\begin{tabular}{lccc}
\hline & Coal & Co-firing & Rice husk (2005 data) \\
\hline $\mathrm{O}_{2}(\%$ vol $)$ & 6.1 & 7.1 & 7.8 \\
$\mathrm{NO}_{\mathrm{x}}(\mathrm{g} / \mathrm{MJ})$ & $11 \times 10^{-3}$ & $9.5 \times 10^{-3}$ & $8.8 \times 10^{-3}$ \\
$\mathrm{CO}(\mathrm{g} / \mathrm{MJ})$ & $3.1 \times 10^{-3}$ & $3.1 \times 10^{-3}$ & $2.8 \times 10^{-3}$ \\
$\mathrm{SO}_{2}(\mathrm{~g} / \mathrm{MJ})$ & $47 \times 10^{-3}$ & $45 \times 10^{-3}$ & $43 \times 10^{-3}$ \\
$\mathrm{Ash}$ content (\% by wt.) & 40 & 30 & $10-15$ \\
\hline
\end{tabular}

\section{Numerical simulation of CPP boiler}

Computational fluid dynamics is an extension of classical fluid dynamics, originating from the amalgamation of classical fluid dynamics and numerical analysis supported by powerful electronic digital computers. CFD is defined as the set of methodologies that enable the computer to provide us with a numerical simulation of fluid flow (Hirsch 2007). CFD is the analysis of systems involving fluid flow, heat transfer and associated phenomena such as chemical reactions by means of computer-based simulation. High quality computational fluid dynamics (CFD) is an effective engineering tool for power engineering industry. It can determine detailed flow distributions, temperatures, and pollutant concentrations with excellent accuracy, and without excessive effort by the software user. In the other words it is the science of predicting fluid flow, heat and mass transfer, chemical reactions and related phenomena.

CFD model is based on fundamental assumptions that allow calculation of spatial and temporal variations of temperature and pressure, gas composition, velocity, particle trajectories and so forth. The numerical solution of Navier-Stokes equations in CFD codes usually implies a discretization method, in which a problem involving calculus is transformed into an algebraic problem which can then be solved by computer by using a solution methodology. A discretization technique and a solution methodology constitute the numerical methodology used to solve a heat transfer and fluid flow problem. Among various discretization methods, the most commonly used methods are the Finite difference method (FDM), the Finite volume method (FVM) and the Finite element method (FEM). During the early days of Computational fluid dynamics (CFD), finite difference methods were the most popular being algorithmically simple, efficient, and accurate. However, they are best used on uniform grids and hence on regular computational domains. With time due to advancements in CFD codes and its application to industrial problems, the need of methods for computing flows in complex geometries arised. In case of using finite difference method to such geometries, we map the complex domain into simple domains by converting it into algebraic expressions and solve the equations. But in such transformation the governing equations become complicated and may lead to a loss of computational efficiency and accuracy. In view of that the finite volume methods can be adopted directly on the physical domain without any transformation. Finite volume methods are essentially a generalization of the finite-difference method, but use the integral form of the governing equations of flow rather than their differential form. This gives greater flexibility in handling complex domains. The FLUENT code, which is used to simulate the flow field, is based on the finite volume discretization scheme (Ravelli et al 2008).

\subsection{Approaches to CFD}

Due to high cost and more time consuming experimentation on fluidization, more researchers are extending their efforts towards developing the mathematical model and numerical 
Table 6. Salient features of CFD analysis done by various researchers so far.

\begin{tabular}{ll}
\hline Reference & Main observations \\
\hline Ravelli et al (2008) & 1. Furnace is difficult to regulate because of the high
\end{tabular}

Ravelli et al (2008)

1. Furnace is difficult to regulate because of the high variability of fuel heat content and slag clustering

2. The freeboard behavior was simulated according to two different operating conditions i.e. minimum and maximum load

3. All the physico-chemical phenomena of main importance are included in the 3D Modeling

Wankhede \& Adgulkar (2008) $\quad$ 1. Eulerian approach has been identified as the most suitable approach for fluid dynamics and heat transfer in fluidized beds

2. Gunn model with kinetic theory of granular flow is appropriate model for modeling heat transfer between multiple phases

3. Heat transfer coefficient has strong influence with rising bubbles near wall of heated pipes

Singh et al (2009)

Agraniotis et al (2010)

Three phase mathematical modeling has been predicted by CFD analysis based on rice husk

2. Velocity of air along the walls in the fluidized bed combustor is nil

3. Velocity of air at the top of tube in FBC is zero or minimum as compared to bed

\section{Main results}

1. High intrinsic reactivity of fuel favours the fast activation of the homogeneous combustion of volatiles

2. At minimum load the maximum temperature in the freeboard reduced $(1450 \mathrm{~K}$ against $1550 \mathrm{~K})$ and combustion is postponed.

3. The maximum load condition assured a more efficient heat transfer from the flue gas to the tubes: the heat flux varied from $-110,000$ to $-60,000 \mathrm{~W} / \mathrm{m}^{2}$

1. The heat transfer coefficient varies drastically with the gas velocity

2. The variation for the heat transfer coefficient with $\mathrm{u} / \mathrm{u}_{\mathrm{mf}}$ is linear

3. Because of cohesive nature, the material shows an increase in heat transfer coefficient between 5 to $10 \mathrm{u} / \mathrm{u}_{\mathrm{mf}}$ and a decrease for upper position

1. Bubbles vary in size along with bed height in fluidized bed combustor based on rice husk

1. Lignite predrying and lignite firing is considered as a significant technological development in future

2. $\mathrm{NO}_{\mathrm{x}}$ emission is increased
2. With the bed super heater tubes, bubbles are formed and erupted at the tubes

3. The bubble flow structure is affected due to the presence of tubes

1. The average temperatures along the furnace height, as well as the fuel's burn out, increase by increasing the cofiring share

2. There is no effect of dry coal coutilization on the boiler's operation and performance due to the low cofiring shares applied 
Table 6. (continued)

\begin{tabular}{|c|c|c|}
\hline Reference & Main observations & Main results \\
\hline Hamzehei et al (2010) & $\begin{array}{l}\text { 1. The kinetic theory of granular flow has been used to } \\
\text { guide the development of appropriate constitutive } \\
\text { laws } \\
\text { 2. The Eulerian-Eulerian model with the standard k- } \varepsilon \\
\text { turbulence model was used for modeling } \\
\text { 3. The work may be extended to 3D gas-solid flows }\end{array}$ & $\begin{array}{l}\text { 1. The pressure drop decreases significantly at the beginning of } \\
\text { fluidization and then fluctuates around a near steady-state } \\
\text { value after about } 3.5 \mathrm{~s} \\
\text { 2. Gas temperature decreases as it moves upward in the reactor } \\
\text { 3. Increase in the gas velocity leads to a decrease in the gas and } \\
\text { increase in the solid particle temperature } \\
\text { 4. There is no significant difference for drag models, all three } \\
\text { drag models are suitable for predicting the hydrodynamics of } \\
\text { gas-solid flows }\end{array}$ \\
\hline Rozainee et al (2010) & $\begin{array}{l}\text { 1. It was observed that the operating conditions giving } \\
\text { the highest residual carbon content corresponds with } \\
\text { the lowest average bed temperature } \\
\text { 2. All ash samples were contaminated with sand due to } \\
\text { the presence of quartz peaks } \\
\text { 3. The residence time of sand particles cannot be } \\
\text { determined distinctly }\end{array}$ & $\begin{array}{l}\text { 1. The secondary air flow rate gave the highest average bed } \\
\text { temperature }\left(680^{\circ} \mathrm{C}\right) \text { and lowest residual carbon content in the } \\
\text { ash }(2.7 \mathrm{wt} . \%) \\
\text { 2. Model IV gave the highest mean residence time of } 52 \mathrm{~s} \\
\text { 3. Residence time of rice husk inside the combustor was lowest }\end{array}$ \\
\hline Singh et al (2013) & $\begin{array}{l}\text { 1. This paper summarized the CFD modeling tool to } \\
\text { study combustion and gasification of fuels in fluidized } \\
\text { bed devices } \\
\text { 2. CFD has played an active part in analysis of the } \\
\text { distribution of products, heat flux, flow, } \\
\text { temperature, ash deposits, CO, SOx and NOx } \\
\text { emissions during combustion and gasification of fuels } \\
\text { in fluidized bed } \\
\text { 3. The CFD model results are satisfactory and have } \\
\text { made good agreements with the experimental data } \\
\text { in many cases. However, the simulations still have } \\
\text { many approximate models as well as some } \\
\text { assumptions }\end{array}$ & $\begin{array}{l}\text { 1. Due to variation in size of biomass particles the Eulerian- } \\
\text { Eulerian approach with biomass considering } \\
\text { combustion/gasification issues in dense fluidized beds is not } \\
\text { possible until wide approximations are chosen } \\
\text { 2. The understanding of Eulerian technique to fluidized beds with } \\
\text { thermo-chemical reactions is still in a development stage } \\
\text { 3. Although there are still some obstacles such as inability in } \\
\text { accurate simulation of large } 3 \mathrm{D} \text { problems on an affordable } \\
\text { computer, in particular, large-scale plants, the trend of } \\
\text { widespread application of CFD in the fluidization industry will } \\
\text { continue in the } 21^{\text {st }} \text { century }\end{array}$ \\
\hline
\end{tabular}


simulation with the help of Computational Fluid Dynamics (CFD) and validating the CFD results with experimental results. In this way, they are able to study large number of parameters in stipulated time and develop the optimized solution to work. A review of the work done by different researchers so far is done and given in table 6.

Due to enormous increase in the computing power and algorithm development, fundamental hydrodynamic, heat transfer and mass transfer modeling of multiphase reactors has become possible. Either of the two approaches is adopted for CFD analysis of gas-solid flows: (1) Eulerian-Eulerian and (2) Eulerian-Lagrengian. Using the Eulerian-Eulerian model, the basic assumption is that gas and solid phases are interpreting continuous. With the LagrengianEulerian models, trajectories of each particle are tracked by solving the individual equations of motion, whereas the gas phase is modelled using the Eulerian framework. CFD simulations for the heat transfer in bubbling fluidized beds for Eulerian-Eulerian model are reported by Kuipers et al (1992) and Schmidt \& Renz (1999) for 2D and Gustavasson \& Almstedt (2000) for 3D.

\subsection{Grid formation of CPP boiler}

Biomass combustion is generally modeled in a similar approach as coal combustion, the reason being that biomass fuels undergo same sequence of pyrolysis, devolatilization and combustion as observed in low-calorific value coal combustion mechanisms. Biomass burning is assumed to happen in two phases; first, a homogeneous combustion phase and second, a heterogeneous combustion phase. In homogeneous combustion, devolatilization of biomass particles takes place and combustion takes place in gaseous phase whereas in heterogeneous combustion, burning of solid char happens. Geometry generation and grid formation of CPP boiler is done in Gambit which is pre-processor of Fluent 6.3 commercial code. CPP, Ambuja generates $30 \mathrm{MW}$ of power running on three boilers. All the boilers are designed for biomass combustion. However in case of less availability of biomass fuel they may run on coal. The geometry of boiler with dimensions and inside components is shown in figure 6. There are four biomass feed

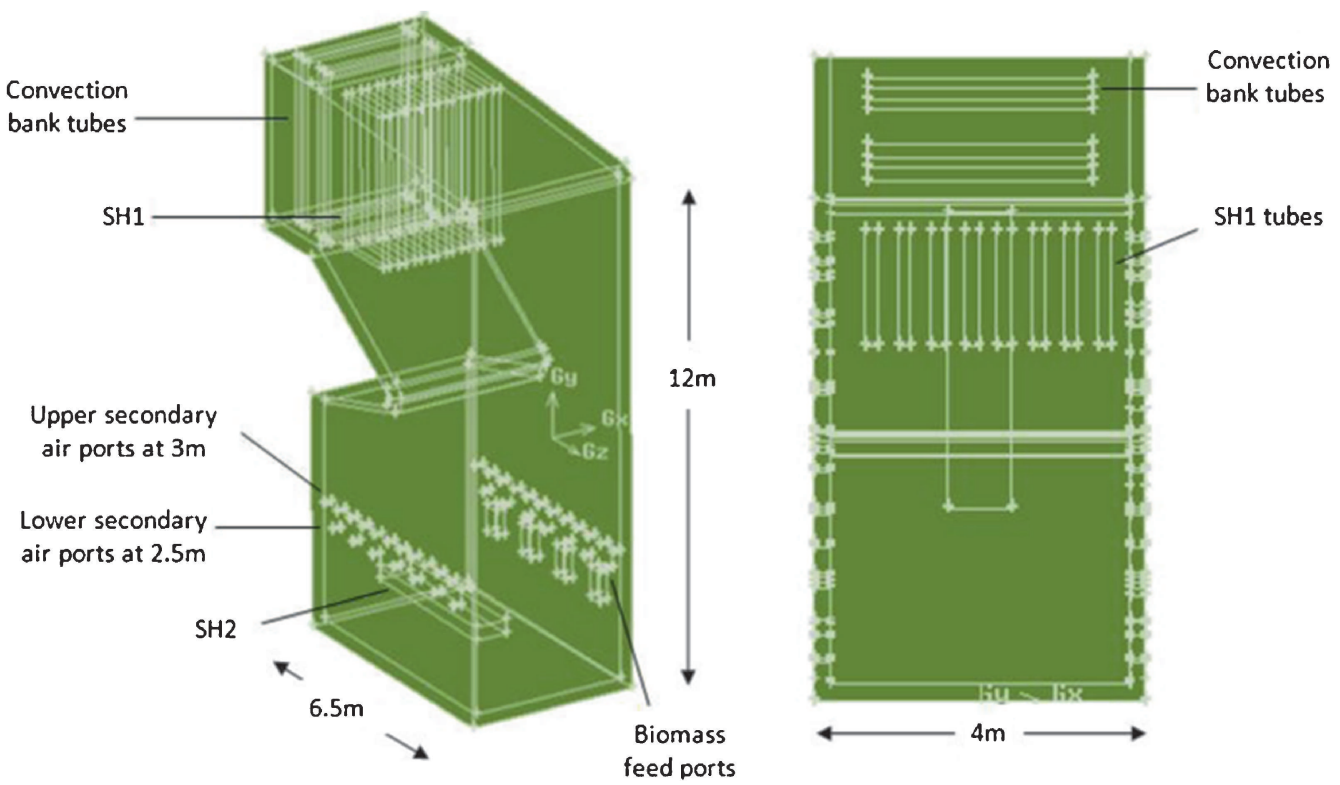

Figure 6. Drawing of CPP boiler and boiler cross section. 
Table 7. Boiler details.

\begin{tabular}{lcc}
\hline Components & Number & Dimensions $(\mathbf{m m})$ \\
\hline Biomass feed ports & 04 & $380 \times 680$ \\
Primary SH coils & 44 & $45(\mathrm{OD}) \times 5$ (thickness) \\
Inbed SH coils & 07 & $51(\mathrm{OD}) \times 6.5$ (thickness) \\
Upper secondary air ports & 12 & 55 \\
Lower secondary air ports & 7 & 55 \\
Convection bank tubes & 32 & $51(\mathrm{OD}) \times 5$ (thickness) \\
\hline
\end{tabular}

ports available for fuel supply. There are twelve upper secondary air ports and seven lower secondary air ports for supplying excess air for complete combustion. There are three Super heaters $(\mathrm{SH})$ installed inside the combustor. One is in bed superheater ( $\mathrm{SH} 2$ ) having seven numbers of coils. Others are primary and secondary superheaters installed at the top of the combustor. For the purpose of analysis primary and secondary super heaters are not shown separately.

After the superheaters, there come convection bank tubes which are also working as a heat sink. The detail of all the components is shown in table 7. During geometry generation, it was found difficult to mesh all the superheater and convection bank tubes separately, by considering them all different volumes. This was happening due to large domain of the boiler and skewness created at the voids at the interface of these tubes and boiler walls at some places. Since, to simplify the boiler geometry, instead of drawing all the superheater tubes and convection bank tubes an equivalent volume of these components is considered and drawn in simpler form. The Grid contains a total of 2,150,127 elements. Out of which 1,821,706 are hexahedral elements and rest 328,421 (15.27\%) are pyramids and tetrahedrons. The mesh near the regions of tubes was controlled in such a manner that at least 12 elements were created around the cross-section of the tube. The grid element has a maximum size of 90 .

Entire modeling of geometry is done in GAMBIT. Meshed geometry incorporating all the components is shown in figure 7(a). The boundary zones are specified as Velocity_Inlet 1, Velocity_Inlet 2, Pressure_Outlet and Walls. The grid is then checked and scaled after which it is exported to the solver, which is FLUENT 6.3.

\subsection{Analysis}

The analysis has been done using Eulerian-multiphase model approach. In this work, standard $\mathrm{k}-\varepsilon$ model has been used for modeling turbulence where the volumetric reaction rates have been controlled using eddy dissipation mechanism. Eddy dissipation mechanism states that the reaction rate is defined by turbulence and concentrations of both reactants and products. Nonpremixed combustion model (NPM) has been applied to simulate combustion in which Mixture fraction/Probability density function (PDF) approach is used. This approach involves the solution of transport equations for one or two conserved scalars (the mixture fractions). Through this approach, instead of solving the transport equations for individual species, the component concentrations of species of interest are derived from the predicted mixture fraction. Therefore, the usually unknown reaction mechanism is not explicitly solved but it is treated using certain system chemistry calculations (e.g. equilibrium assumption and non-equilibrium chemistry). Physical properties of chemical species and equilibrium data are retrieved from the chemical database while the interaction of turbulence and chemistry is obtained with a probability density function or PDF. 


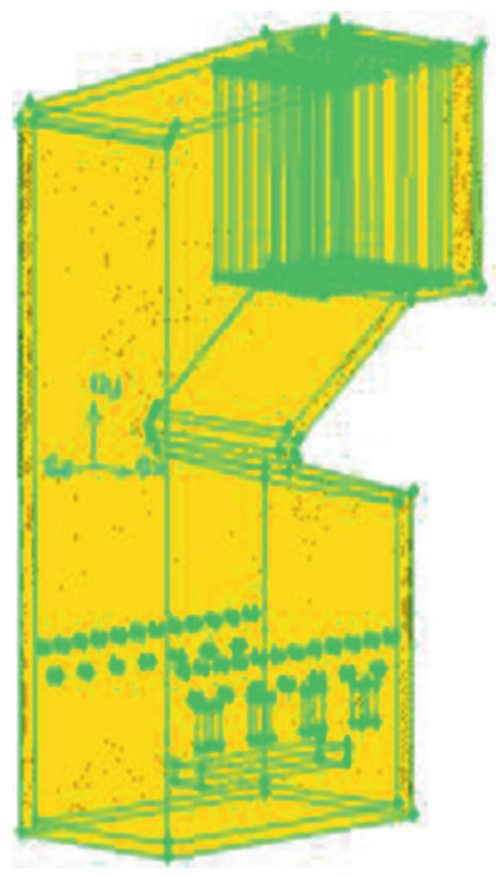

(a)

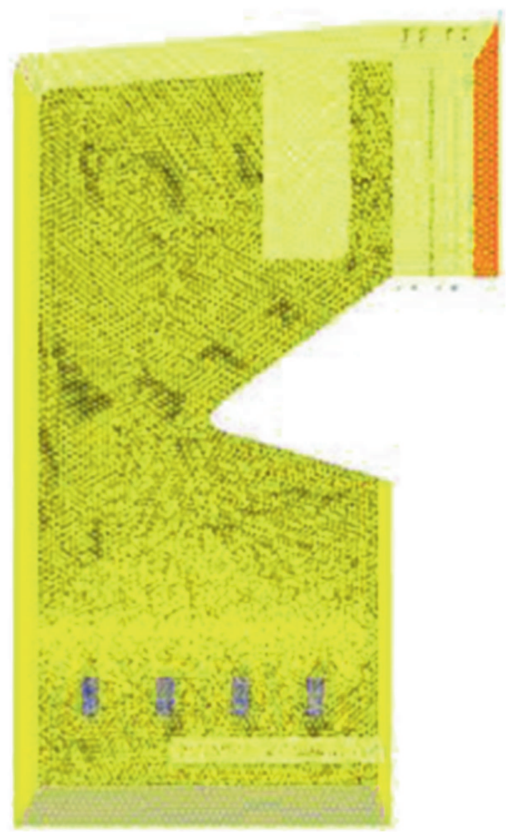

(b)

Figure 7. (a) Meshed geometry. (b) Grid.

The PDF modeling approach is considered computationally efficient method because a large number of species transport equations need not required to be unnecessarily solved. The basis of the mixture fraction approach is that, the thermo-chemical state of the fluid is related to a conserved scalar quantity known as the mixture fraction, $f$. Being a conserved scalar quantity, the value of $f$ at each point in the flow domain is computed in FLUENT through the solution of the conservation equation for mean value of $f$ in the turbulent flow field using following relation:

$$
\frac{\partial}{\partial_{x_{i}}}\left(\rho u_{i} \bar{f}\right)=\frac{\partial}{\partial_{x_{i}}}\left(\frac{\mu_{t}}{\sigma_{t}} \frac{\partial \bar{f}}{\partial_{x_{i}}}\right)+\mathrm{S}_{\mathrm{m}},
$$

where ui is fluid velocity at any point in turbulent field, $\bar{f}$ is mean value of mixture fraction, $\mu_{t}$ is turbulent viscosity and $\sigma_{t}$ is a constant. $\mathrm{S}_{\mathrm{m}}$ represents the transfer of mass from reacting particles into the gas phase.

In addition to the above equation, a conservation equation for the mixture fraction variance, $\overline{f^{\prime} 2}$ is also solved:

$$
\frac{\partial}{\partial_{x_{i}}}\left(\rho u_{i} \overline{f^{\prime} 2}\right)=\frac{\partial}{\partial_{x_{i}}}\left(\frac{\mu_{t}}{\sigma_{t}} \frac{\partial \overline{f^{\prime} 2}}{\partial_{x_{i}}}\right)+C_{g} \mu_{t}\left(\frac{\partial \bar{f}}{\partial_{x_{i}}}\right)^{2}-C_{d} \rho \frac{\varepsilon}{k} \overline{f^{\prime 2}}
$$

where the constants $\sigma_{t}, \mathrm{Cg}$ and $\mathrm{Cd}$ are given the default values by solver which is FLUENT itself. The mixture fraction variance is used to describe the turbulence-chemistry interaction. 
Table 8. Inputs for NPM.

\begin{tabular}{lcc}
\hline Species & $\begin{array}{c}\text { Primary fuel (Coal) mass } \\
\text { fraction }\end{array}$ & $\begin{array}{c}\text { Secondary fuel (Biomass) } \\
\text { partial fraction (avg. value) }\end{array}$ \\
\hline Carbon & 0.7586 & 0.4135 \\
Hydrogen & 0.0553 & 0.045 \\
Oxygen & 0.1518 & 0.35 \\
Nitrogen & 0.0343 & 0.005 \\
\hline
\end{tabular}

Calculation of a single conserved scalar field, $f$ also derives of other important scalars which are density and temperature without the need to solve their respective transport equations. Provided the description of the reacting system chemistry, the mixture fraction value at each point in the flow field can be used to compute the instantaneous values of these scalars. If a secondary stream is included in the system, then the instantaneous values will depend on fuel mixture fraction $f_{f u e l}$ the secondary partial fraction $p_{s e c}$, and enthalpy $H^{*}$.

$$
\phi_{i}=\phi_{i}\left(f_{f u e l}, p_{s e c}, H^{*}\right)
$$

where $\Phi$ represents the instantaneous species concentration and $H^{*}$ is given by

$$
H^{*}=\sum_{i} m_{i} H_{i}=\sum_{i} m_{i}\left[\int_{T_{\text {ref } i}}^{T} c_{p, i} d t+h_{i}^{o}\left(T_{\text {ref } i}\right)\right]
$$

Input values for co-firing in NPM are given in table 8. In NPM, the input is given in terms of chemical composition of fuel. As mentioned earlier, Sulphur is having a negligible fraction in f-grade coal and biomass, its value has been ignored in data input. NPM considers ash less and moisture less combustion (FLUENT user's guide 2006), that is why the fractions of carbon, hydrogen, oxygen and nitrogen are calculated accordingly primarily for coal because in biomass they are having considerably very less fraction. For coal firing alone, secondary fuel stream is not considered.

During each iteration, the values obtained for the variables should get closer and closer to converge the solution. For simple problems especially cold flows without combustion the relaxation factor can be kept on default value. Sometimes for various reasons, the solution can become unstable due to the complex nature of the process. In that case a relaxation factor is used to cut out steep oscillations and stabilize the solution. In our case, a under relaxation factor of 0.95 has been taken. The other parameters taken during simulation are shown in table 9. Combustion in the furnace takes place at very high temperatures, thus radiative heat transfer is considered a very prominent process inside the boiler. Standard P1 radiation model has been used for modeling radiation depending upon the computation space available, accuracy required and data reported in literature (Hamzehei et al 2010; Walsh 2006).

Table 9. Model parameters.

\begin{tabular}{lccc}
\hline Bulk density & $1100 \mathrm{Kg} / \mathrm{m}^{3}$ & Mass diffusivity & $2.88 \times 10^{-5} \mathrm{~m}^{2} / \mathrm{s}$ \\
Gas density & $1.29 \mathrm{Kg} / \mathrm{m}^{3}$ & Convergence criteria & 0.001 \\
Gas viscosity & $1.72 \times 10^{-5} \mathrm{~kg} / \mathrm{m}-\mathrm{s}$ & Turbulence intensity & $10 \%$ \\
Under relaxation factor & 0.95 & Turbulent kinetic energy & $5.79 \mathrm{~m}^{2} / \mathrm{s}^{2}$ \\
\hline
\end{tabular}



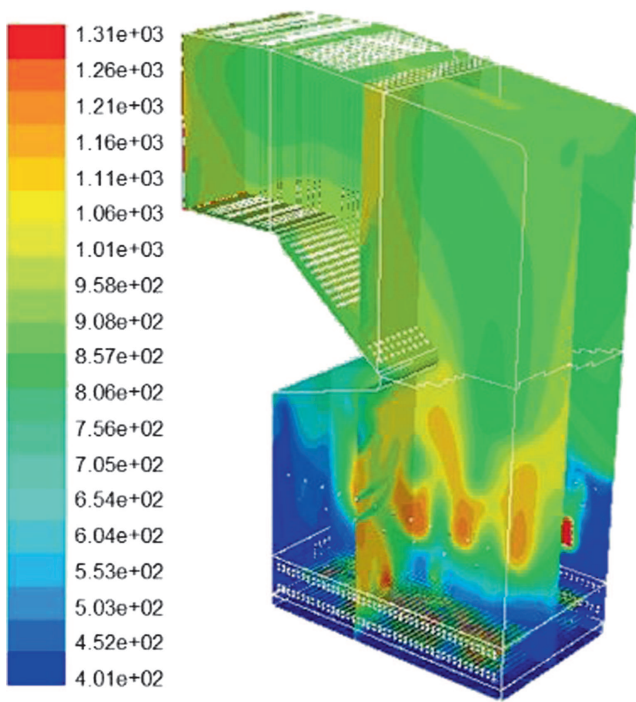

(a)

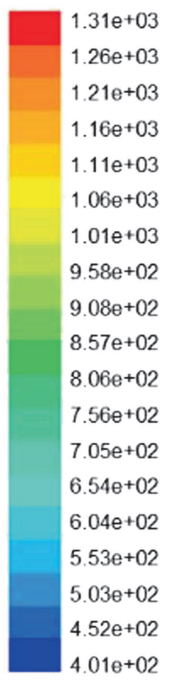

Figure 8. Temperature contours (a) Co-firing. (b) Coal firing.

\section{Results and discussions}

Figure 8(a) is showing temperature contours of boiler working on cofiring, in which biomass is supplied from biomass ports at a height of $2 \mathrm{~m}$ from the bed. Figure $8(\mathrm{~b})$ is showing temperature profile of another boiler running on coal. As discussed earlier, the bed temperature in case of coal firing remains more in comparison to cofiring because biomass burns in the freeboard zone. However, in case of cofiring the temperatures along the biomass ports are showing a higher range due to instantaneous burning of biomass in suspension in the form of flame. The CPP boiler bed is divided into four equally spaced regions simply based on the uniform location of temperature sensors and coal feed ports. Figure 4 is showing eight temperature values of these regions having two values each. The bed temperatures in case of cofiring were in between $750^{\circ} \mathrm{C}$ and $800^{\circ} \mathrm{C}$ and in case of coal firing the bed temperatures were found in between $900^{\circ} \mathrm{C}$ and $950^{\circ} \mathrm{C}$ except few absurd readings. The simulation results show the higher range of bed temperatures in case of coal firing as comparable to cofiring. However, few lower range sections are also appearing due to presence of primary air. The simulation results are showing actual process trends, with an agreement to real process.

\section{Conclusions}

1. During plant investigations, it was found that due to negligible sulphur content in biomass and very less sulphur content in coal (f-grade) used at CPP, the $\mathrm{SO}_{2}$ formation remains within permissible limits. That is why no desulphurization unit is working presently at CPP.

2. Due to lower bed temperatures during biomass burning $\mathrm{NO}_{\mathrm{x}}$ formation also remains within permissible limits. 
3. During simulation of boilers, trend of temperature contours for both the cases was found in agreement with real process showing a higher range of bed temperatures in case of coal firing as comparable to co-firing.

\section{Acknowledgements}

The authors would like to appreciate the help extended by the authorities of Ambuja Cement Limited for collection of data, samples, providing information and facts about the plant. In special authors would like to thank to Mr. RC Kothari, Senior President, Ambuja Cement Limited, Mr. BS Rana, GM (CPP) and Er. Vijay Verma.

\section{References}

Agraniotis M, Stamatis D, Grammelis P and Kakaras E 2010 Dry lignite cofiring in a greek utility boiler: Experimental activities and numerical simulations. Energy Fuels 24: 5464-5473

Demires A 2005 Biomass co-firing for boilers associated with environmental impacts. Energy Sources 27: $1385-1396$

FLUENT user's guide 2006 vols. 1-2. Lebanon

Gustavasson M and Almstedt A E 2000 Numerical simulation of fluid dynamics in fluidized beds with horizontal heat exchanger tubes. Chem. Eng. Sci. 55: 857-863

Hamzehei M, Rahimzadeh H and Ahmadi G 2010 Computational and experimental study of heat transfer and hydrodynamics in 2d gas-solid fluidized bed reactor. Ind. Eng. Chem. 49: 5110-5121

Hirsch C 2007 Numerical computation of internal and external flows. USA: Butterworth-Heinemann

Indian Network for Climate Change Assessment (INCCA) 2010 India Greenhouse gas emissions 2007, Ministry of Environment \& Forests, India

Kaur G, Singh J and Sood A 2006 Power generation potential from crop biomass in Punjab. Agri. Eng. Today 30: 5-6

Kuipers J A M, Prins W and Van Swaaij W P M 1992 Numerical calculation of wall to bed heat transfer coefficients in gas-fluidized beds. AIChE J. 38: 1079-1091

Madhiyanon T, Sathitruangsak P and Soponronnarit S 2009 Co-combustion of rice husk with coal in a cyclonic fluidized bed combustor. Fuel 88: 132-138

Natrajan E, Nordin A and Rao A N 1998 Overview of combustion and gasification of rice husk in fluidized bed reactors. Biomass Bioenergy 14: 533-46

Ravelli S, Perdichizzi A and Barigozzi G 2008 Description, applications and numerical modeling of bubbling fluidized bed combustion in waste-to-energy plants. Prog. Energy Combust. Sci. 34: 224-253

Rozainee M, Ngo S P, Salema A A and Tan K G 2010 Computational fluid dynamics modeling of rice husk combustion, in a fluidized bed combustor. Powder Technol. 203: 331-347

Sathitruangsak P, Madhiyanon T and Soponronnarit S 2009 Rice husk co-firing with coal in a short combustion chamber fluidized bed combustor (SFBC). Fuel 88: 1394-1402

Schmidt A and Renz U 1999 Eulerian computation of heat transfer. Chem. Eng. Sci. 54: 5515-5522

Singh R I, Mohapatra S K and Gangacharyulu D 2009 CFD analysis of bubbling fluidized bed combustion using rice husk. Proceedings of $20^{\text {th }}$ international conference on FBC 6: 857-863

Singh R I, Brink A and Hupa M 2013 CFD modeling to study fluidized bed combustion and gasification. App. Thermal Eng. 52: 585-614

Sun P, Hui S, Gao Z, Zhou Q, Tan H, Zhao Q and Xu T 2013 Experimental investigation on the combustion and heat transfer characteristics of wide size biomass co-firing in $0.2 \mathrm{MW}$ circulating fluidized bed. App. Thermal Eng. 52: 284-292

Walsh A R $20067^{\text {th }}$ European conference on industrial furnaces and boilers, Porto, Portugal, 1-11

Wankhede U S and Adgulkar D D 2008 CFD simulations of heat transfer in a bubbling fluidized bed for different materials. Emerg. Trends in Eng. Technol.1094-1098

Werther J, Saenger M, Hartge E U, Ogada T and Siagi Z 2000 Combustion of agricultural residues. Prog. Energy Combust. Sci. 26: 1-27 